American Journal of Applied Sciences 5 (5): 468-472, 2008

ISSN 1546-9239

(C) 2008 Science Publications

\title{
Investigation of The Bubble Foam Separation Technique To Extract Protein From Whey
}

\author{
Mohammed Matouq \\ Al-Balqa Applied University, Chemical Engineering Department, \\ Faculty of Engineering Technology, P.O. BOX 4486, Amman 11131, Jordan
}

\begin{abstract}
Separation of proteins from whey; namely $\alpha$ - Lactoglobulin and $\beta$ - Lactalbumin was obtained using the bubble foam column technique. Two types of whey were conducted in this study; yogurt whey and cheese whey. The effect of gas flow-rate and the height of the whey (liquid holdup) inside the column were studied at room temperature and at constant $\mathrm{pH}$ of whey. Whey used here obtained from local dairy factory as waste, and was used to investigate the performance ability of bubble column to extract very low concentration portion from waste. Enrichment ratio showed that the possibility of extracting protein from whey was high. Results showed that enrichment ration was higher for yogurt whey from that of cheese whey. The results also showed that the efficiency of separation of these proteins increased with decreasing both the air flow-rate, and wheys volume inside the column. The maximum amount of protein obtained at air flow-rate $=0.2 \mathrm{Liter} / \mathrm{min}$ at experimental condition.
\end{abstract}

Keywords: Whey, Foam Separation, Bubble Column, Waste Recovery, clean technology, environmental management

\section{INTRODUCTION}

Foam fractionation is a well-documented protein purification technique, which has potential use in the preliminary stages of the downstream processing of recombinant and other proteins. The advantages of the process include, ease of operation, mechanical simplicity and therefore low cost compared to existing purification methods. Much research has been conducted using single protein solution but limited work exists for protein mixtures. In order to successfully purify one protein component from any mixture of proteins, the surface activities of proteins must differ.

Foam fractionation or adsorptive bubble separation processes had been widely applied in ineral floatation. The techniques were based on the difference of surface tension between materials to be separated. This technique is also applied in solid wastewater treatment. The recovery or removal of dilute organic compounds contained in industrial wastewater is possible, because organic compounds often show low surface tension and could be enriched at air-water interface ${ }^{[1]}$

Burapatana et. $a l^{[2]}$, used foam fractionation to recover cellulase from an aerated water solution effectively. The addition of a surfactant increased the foamate volume and enhanced the concentration of cellulase.
Vorukan and Prokop ${ }^{[3]}$ investigated foam fractionation to recover low concentration cellulose effectively. They found that separation by foam without surfactant could not purify since the cellulose alone could not produce enough amount of foam. Addition of surfactant, can increase the foamate volume and enhance the enrichment value.

Foam fractionation plays an important role in diverse fields both for recovering valuable solutes and for rejecting impurities and pollutants in dilute solutions. A continuous recovery of $\mathrm{Au}(\mathrm{III})$ via foam separation from its hydrochloric acid solutions was studied using a nonionic surfactant by Akita et al ${ }^{[4,5,6]}$ and was compared with other separation techniques. They claimed that about $90 \%$ of $\mathrm{Au}$ (III) recovered in the foamate phase with high selective recovery of $\mathrm{Au}(\mathrm{III})$ from multi-metals solution.

Kumar et. $a l^{[7]}$ investigated separation of proteins from their binary mixtures (BSA-casein, BSAlysozyme) using static foams. They found out that there is a strong interaction between the two proteins and the presence of one strongly influences the adsorption of the other. The concentration of a protein in the foam depends not only on the amount adsorbed at the interface but also on the liquid associated with it.

Perihan et al. ${ }^{[8]}$ investigated the feasibility of foam fractionation to separate total whey proteins and single 
fractions. The investigation focused on the effects of different process parameters such as the $\mathrm{pH}$ value, the initial protein concentration, the flow rate and the addition of sodium dodecyl sulfate concentration as a surfactant. Their results showed that whey proteins could be almost completely enriched into the foam fraction at $\mathrm{pH}$ values between 2 and 3 .

Whey is the residual liquid substance that is obtained by separating the coagulum from milk during cheese making. Most commercial whey supplements are derived from cow's milk, which is comprised of $6.25 \%$ protein: $20 \%$ in the form of whey. It is a complex ingredient made up of protein, lactose, fat and minerals. Protein is the best-known component of whey and is made up of many smaller protein sub-fractions such as: $\quad \beta$-lactoglobulin, $\alpha$-lactalbumin, immunoglobulins (IgGs), glycomacropeptides, bovine serum albumin (BSA) and minor peptides such as lactoperoxidases, lysozyme and lactoferrin. Each of the sub-fractions found in whey has its own unique biological properties.

$\beta$-Lactoglobulin binds and stabilizes fat-soluble vitamins (e.g., A and D). This makes it an excellent source for protein fortification in low-fat nutraceutical beverages with added fat-soluble vitamins.

$\alpha$-Lactalbumin is quite similar in structure to human milk and is readily digestible. It is often used in infant formulas to make them more like human milk. Since it's not as easily heat-denatured as $\beta$-lactoglobulin, $\alpha$ lactalbumin is the protein of choice for clear sports/nutraceutical beverages.

The goal of the current study is to examine the use of foam fractionation to reduce the volume of whey wastes from dairy industry via concentration.

Here the separation of protein was conducted in bubble foam column, the industrial application of such techniques is in a great advantage. The bubble column operations and design are easier than other processes used to recover or separate the proteins, like ultrafiltration or membrane. This can be mainly attributed to low operational and maintenance cost for bubble column. The efficiency of proteins separation in bubble column is also promising.

\section{MATERIALS AND METHODS}

Figure 1 shows the apparatus used to conduct experimental work. The apparatus made of $50 \mathrm{~mm}$ internal diameter Pyrex Glass column opened from the two sides with an external diameter of $55 \mathrm{~mm}$ and $650 \mathrm{~mm}$ long. At the upper side end of the column a Utube glass was fitted to the column. A gradual reduction in the connected tube was accomplished till it reached $10 \mathrm{~mm}$ external diameter at its final stage so as to break the foam. At the end of $U$ tube the foam was collected and broken down during the experiment. The lower part of the column was fitted with a glass frit of Pyrex sintered disc of porosity $16-40 \mu \mathrm{m}$ (grade 3). Two openings were fixed to the column to fill and empty the column.

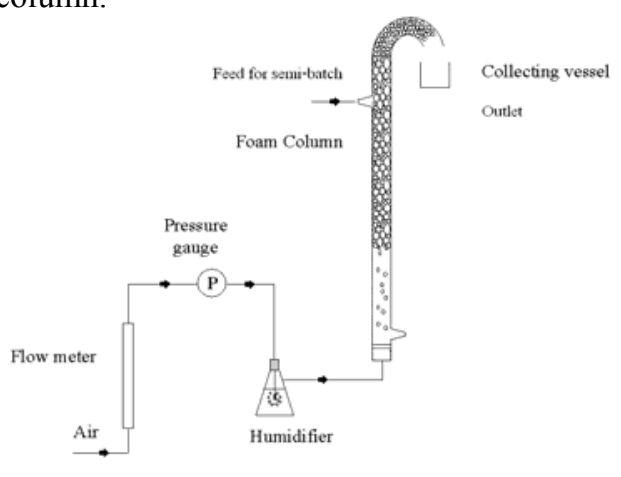

Fig. 1: Experimental setup for the semi-batch process to separate protein from whey

Collected whey was obtained from the dairy factory near to our Engineering Faculty, as waste. The whey is the product of either of cream yogurt or white cheese. Before any conducted experiment the $\mathrm{pH}$ for both cheese whey and yogurt were measured at room temperature. In most conduced experiments the temperature was found to be around $25^{\circ} \mathrm{C}$. The $\mathrm{pH}$ for whey yogurt was measured by a $\mathrm{pH}$ meter of (The Oyster- $\mathrm{pH} /$ conductivity+ TDS Meter) and found to be within the range of (3.5-4.25). For the cheese whey the $\mathrm{pH}$ found equal to 3.83 .

Air was introduced via compressor through a plastic pipe and was measured by a flow meter. The air volumetric flow-rate was set at $0.2 \mathrm{liter} / \mathrm{min}$ all over the experiment.

The yogurt whey that obtained from the commercial factory was poured inside column without any further treatment, from the top opening. Three different heights $(250,200$, and $150 \mathrm{~mm})$ of liquid whey inside the column were selected as one of the variable parameters to be investigated, while keeping the air velocity constant at 0.2 liter/min. Shortly after the compressor started, bubble was noticed to be formed and due to the continuous airflow foam was hold up till it broke at the top of the collected end point. A glass beaker was adjusted to the column to collect foamate.

When the quasi-steady state assumed to be reached and the collected foamate samples were taken and analyzed by using spectrophotometer, with two cells 
chamber, each $5 \mathrm{ml}$ volume crystals. The analysis was done at $280 \mathrm{~nm}$ wavelengths. The same procedure was repeated for the cheese whey.

\section{RESULTS AND DISCUSSIONS}

Yogurt Whey: Figure 2 shows that when decreasing air flowrate, the enrichment value is increasing. The figure also reveals that the best separation for protein obtained at air flowrate of $0.20 \mathrm{l} / \mathrm{min}$. No experimental works were conducted below this flowrate value. Below this value it was noticed that the whey started to leak through the frit filter, and preventing| air from flowing through pipe feed. When the air flowrate reached 1.85 $1 /$ min, the enrichment value almost closed to 1 , which means that above this gas flow, the separation is almost difficult. For this reason all experimental work will be conducted at a lower value of $1.85 \mathrm{1} / \mathrm{min}$, and the maximum gas flow will be considered here at 1.45 $1 / \mathrm{min}$. These values will consider as best working conditions for air flowrates used to produce bubble inside the column. Figure 2, indicates that there is a trend of decreasing in the enrichment value as the whey volume (height of whey multiplied by the column cross section area) increasing, while keeping the air flowrate at constant flow. The liquid holdup $\left(\mathrm{e}_{l}\right)$ defined here as the volume of liquid divided by the total volume of the empty column, consequently the gas holdup will be 1$\mathrm{e}_{l}$. This behavior can be noticed when experimental results re-plotted again as illustrated in figure 3

Whey of cheese: Figure 4, shows the result for the separation of protein from cheese whey. The figure indicates that as the whey volume increases, the enrichment value decreases at constant air flowrate. This result refers to the same reasons that mentioned above for the yogurt whey. Moreover, cheese whey produced less foam in comparison to that of whey's yogurt. However, it was noticed that both cheese whey and yogurt whey had the same dynamic behavior toward enrichment ratio. This can be clearly noticed by comparing both Fig. 2 and Fig. 4. In addition to that, the maximum enrichment values are higher for whey's yogurt than for that of cheese, due to the higher ability of yogurt whey to generating foam inside the column. Figure 5 shows the result of enrichment value for cheese whey. Here it is interesting to mention that when there is enough self foam generation (in case of whey yogurt) the enrichment value will be higher, as it can be revealed by comparing both figures 2 and 4 , which means self-foam generation will give better enrichment values. Moreover, when the air flowrate lowered, enrichment value increased. Although the difference in enrichment value can not be noticed significantly over the increasing air flowrate range from 0.911 to $1.45 \mathrm{l} / \mathrm{min}$ at the same liquid hold.

It is clear that the maximum air flowrate was $1.851 / \mathrm{min}$, for all cheese whey volumes. This indicates that above this value, no separating for protein from the whey can be obtained. The reason can be attributed to the fact that, when the air flowrate increases the chance for the protein molecules to be absorbed at the bubble surface will be less, hence all the collected foam will contain less amount of protein and this will decrease the enrichment ratio. Moreover, the higher air flow will give bigger bubble size with less protein absorption rate on the surface of the bubble. This leads to draw a conclusion, at low air flowrate, better mixing for the substances inside the column will be obtained, consequently there will be enough time for proteins to transfer from bulk solution and to be absorbed on the surface of the bubble, to go upward of the top of the column to generate foamate. In addition to that increasing the air flowrate will have its significant effect on diffusion rate from the bulk to the bubble surface and consequently this will lower the enrichment value.

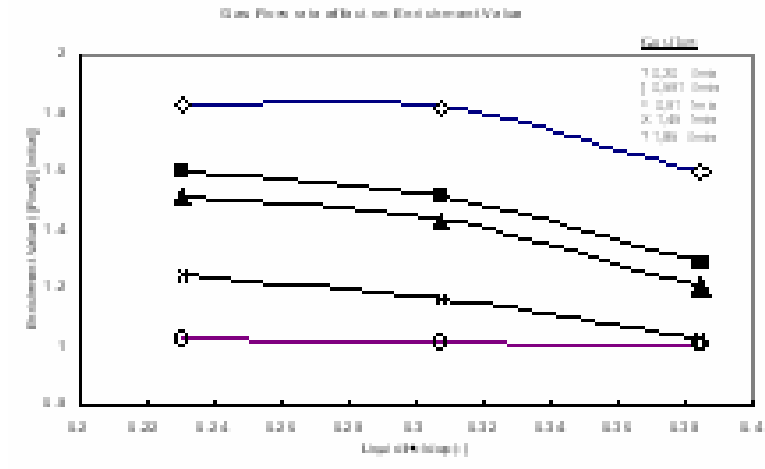

Fig. 2: The effect of liquid holds up on the enrichment value at different constant air flow rates

From figures 2 and 3 , it is clear that the enrichment value increasing, with the decrease in the whey volume inside the column (at constant air flowrate). These obtained values for enrichment values are in a good agreement with those in literature, i.e., Zaid and Hosasin, ${ }^{[9]}$, Hossain and Fenton ${ }^{[10]}$. In their investigation they got 2-8 enrichment value, within $\mathrm{pH}$ ranges of 5-10 for extracting single protein from a mixture of water and protein.

Both yogurt and cheese whey's experiments showed that as the height of the whey inside the column increases, the proteins concentration in the foamate 
decreases. This is true due to the fact that, as the height increases the zone available for separation and to be enriched by reflux will be less. According to these results, it is better to keep the height as much as lower than half of the column, to enhance the separation zone and to keep the gas flow as low as it is possible, say $0.20 \mathrm{l} / \mathrm{min}$.

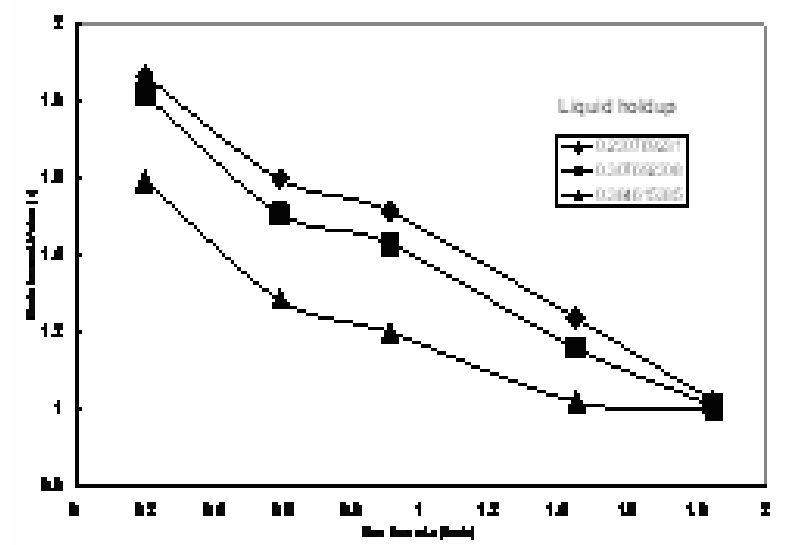

Fig. 3: The effect of air flowrate at constant liquid holdup on the enrichment value for yogurt whey

In the case of cheese whey, the results showed that there are less foam generation, even when the air flowrate was increasing several times higher from of that for yogurt whey. In addition to that, the same value for the air flowrate used in the yogurt whey's experiments was not able to increase the enrichment value for cheese whey. The enrichment value will be less when the whey volume inside the column is higher. This behavior was the same as explained before for the yogurt whey, adding to that less foam generation.

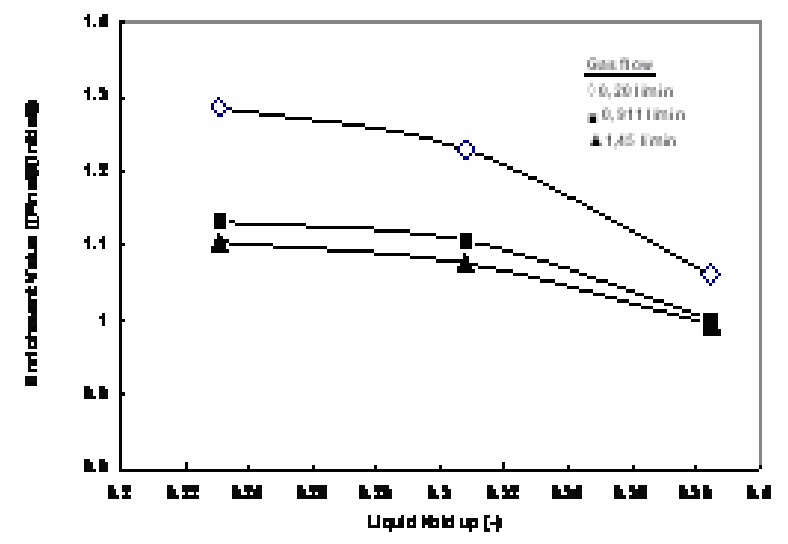

Fig. 4: The effect of liquid holdup on the enrichment value for cheese whey at constant gas flow rate

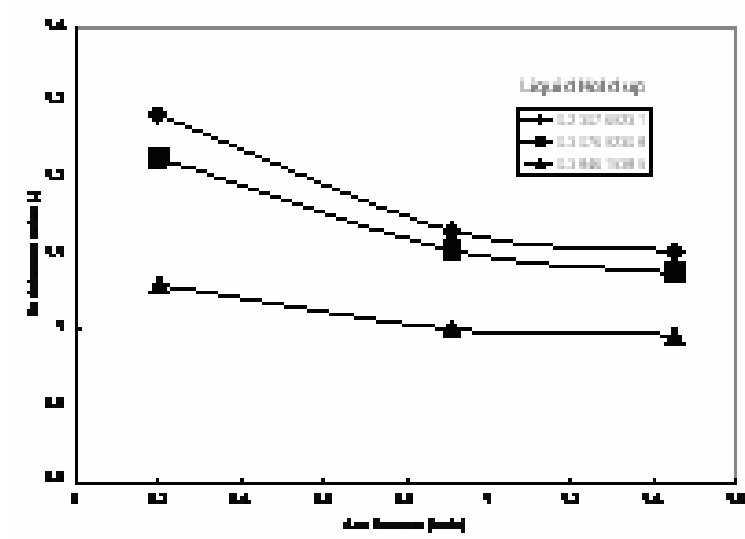

Fig. 5: The effect of air flowrate on the enrichment value for cheese whey at constant liquid holdup

\section{CONCLUSIONS}

Separation of protein from both yogurt whey and cheese whey were successfully obtained from whey waste. Whey cheese gives less foam during experimental works, compared to yogurt whey. This has its effect on the enrichment value. It was noticed that higher enrichment value was obtained for yogurt whey than that of cheese whey. The results showed that there is a limited value for air flowrates above of that no separation could be obtained and this value was found equal to $1.85 \mathrm{l} / \mathrm{min}$. Although cheese whey contains higher protein content in the original sample compared to yogurt's whey, better protein separation obtained for yogurt whey. Cheese whey generates less foam, compared to yogurt this will make bubble foam separation not suitable to extract protein without adding foaming agent, this is due to the high concentration of fat in the cheese whey that breaks down foam and decreases its stability.

As the height decreases, the amount of separated protein increases, then the efficiency of the foam separation process increases too. The same was noticed when the gas flow rate decreases, the amount of separated proteins increases

\section{REFERENCES}

1. Aubrey Shea, J.N. Swamy, Czarena Crofcheck, 2005. Concentration of Whey Solutions by Foam Fractionation. The Annual Meeting Cincinnati, Ohio

2. Burapatana V., Prokop A., and Tanner R. 2005. Enhancing Cellulase Foam Fractionation with Addition of Surfactant Applied Biochemistry and Biotechnology, Vol.122, No. 1-3, 541-552 
3. Vorakan B., Prokop A., 2005. Comparison of the Activity Reduction Occurring in Two DetergentAssisted Protein (Cellulase and Lysozyme) Foam Fractionation Processes. Sep. Sci. Technol, 40, 2445-2453,

4. Akita, S., Rovira, M., Sastre, A. M. and Takeuchi, H., 1998. Cloud Point, Extraction of Gold (III) with Nonionic Surfactant - Fundamental Studies and Application to Gold Recovery from Printed Substrates. Sep. Sci. Technol., 33, 2159-2177.

5. Akita, S., Yang, L. and Takeuchi, H., 1997. Micellar-enhanced Ultrafiltration of Gold (III) with Nonionic Surfactant. J. Membrane Science, 133, 189-194

6. Akita, S., Yang, L. and Takeuchi, H., 1996. Solvent Extraction of Gold (III) from Hydrochloric Acid Media by Nonionic Surfactant. Hydrometallurgy, 43, 37-46.
7. Kumar, R; Bhattacharjee S., Gandhi, K S, 2001. Modelling of protein mixture separation in a batch foam column. Chem. Eng. Scie., 56 5499-5510.

8. Perihan E.; Backleh-Sohrt M.; Parlar H., 2005. High efficiency enrichment of total and single whey proteins by $\mathrm{pH}$ controlled foam fractionation. Int. Jour. Food Scie. Nutrition, 56, 223-229.

9. Zaid S. Saleh M. Hosaain 2001. A Study of the Separation of Proteins from Multicomponet Mixtures by a Semi-Batch Foaming Process. Chem. Eng. Proce. 40, 371-378.

10. Hossain MD. Monwar, G. Fenton, 1998. Concentration of Protein from Single Componet Solution Using Semibatch Foaming Preocess. Sep. Scie. Tech. 33, 11, 1703-1721. 